\title{
Abordagem Pancrônica à Gramaticalização de Daí como Conector
}

\author{
Maria Alice TAVARES \\ Universidade Federal do Rio Grande do Norte
}

Resumo: Em decorrência da gramaticalização, a forma daí foi estendida a diversos empregos gramaticais no português brasileiro. Sob os auspícios do quadro teórico do funcionalismo lingüístico, investigo esses processos de mudança. Para tanto, utilizo: (i) dados extraídos de textos escritos em português do século XIII ao século XX; (ii) 48 entrevistas do Banco de Dados VARSUL, que foram coletadas ao longo da última década do século XX. Com base em evidências sintáticas, semânticas e pragmáticas, proponho trajetórias provavelmente seguidas por daí, partindo de usos dêiticos espaciais e chegando a usos conectivos, em que estabelece elos entre segmentos do discurso. Quatro mecanismos parecem estar envolvidos nesses processos de mudança: metáfora, metonímia, reanálise e analogia.

Palavras-chave: daí; gramaticalização; mecanismos de mudança

\begin{abstract}
As an outcome of grammaticalization, the form dai has been conveyed to several grammatical functions in Brazilian Portuguese. Under the theoretical guideline of linguistic functionalism, I investigate these processes of change. To this end, I make use of: (i) data from texts written in Portuguese from XIII century to XX century; (ii) 48 interviews from the VARSUL Data Base, which were collected during the last decade of the XX century. Based in syntactic, semantic and pragmatic evidence, I propose trajectories probably followed by dai from spatial deictic uses to connective ones, establishing cohesive links between discourse segments. Four mechanisms seem to act over these change processes: metaphor, metonymy, reanalysis and analogy.
\end{abstract}

Keywords: daí, grammaticalization; mechanisms of change

Resumen: En consecuencia de la gramaticalización, la forma daíse ha extendido a múltiples usos gramaticales en el portugués brasileño. Bajo el auspicio del marco teórico del funcionalismo lingüístico, investigo 
esos procesos de cambio funcional. Para ello, uso: (i) datos sacados de textos escritos en portugués del siglo XIII al siglo XX; (ii) 48 entrevistas del Banco de Dados VARSUL, recolectadas a lo largo de la última década del siglo XX. Basándose en evidencias sintácticas, semánticas e pragmáticas, propongo unas trayectorias probablemente seguidas por dai partiendo de uso deícticos espaciales y llegando a usos conectivos, donde estabelece eslabones entre segmentos del discurso. Cuatro mecanismos parecen estar relacionados con esos procesos de cambio: metáfora, metonimia, reanálisis y analogía. ${ }^{1}$

Palabras clave: daí; gramaticalización; mecanismos de cambio

\section{Introdução}

Since grammar is always emergent but never present (HOPPER, 1987, p. 142), there is not much use in forcing into the straitjacket of dichotomies such as that between diachrony and synchrony. [...] since a linguistic element such as a word is capable of acquiring and retaining new senses without losing the old ones, its study requires a panchronic perspective.

(HEINE et al., 1991, p. 259)

Uma forma lexical que seja freqüentemente utilizada em contextos comunicativos particulares pode vir, no curso do tempo, a receber uma função gramatical e, uma vez integrada à gramática, pode ser estendida para funções ainda mais gramaticais. A esse fenômeno dá-se o nome de gramaticalização, processo caracterizado por um subconjunto de mudanças recorrentes translingüisticamente, que envolvem correlações, ao longo do tempo, entre alterações semânticas, morfossintáticas e, às vezes, fonológicas, todas induzidas pelos contextos de uso das formas relevantes. Entre as alterações pelas quais uma forma em gramaticalização tende a passar estão: (i) desenvolvimento unidirecional no plano semântico, indo de significados concretos/lexicais para significados abstratos/gramaticais; (ii) ganho de propriedades morfossintáticas típicas da categoria gramatical para a qual está migrando e, em contraparte, perda de propriedades típicas de seu emprego fonte lexical; (iii) erosão, com a perda de substância fonética.

\footnotetext{
${ }^{1}$ Agradeço a tradução do resumo para o espanhol à professora Maria Avany
} Peixoto dos Santos. 
$\mathrm{Na}$ lingǘstica funcional, os estudos sobre a gramaticalização têm ocupado um lugar de destaque desde a década de $80 .{ }^{2}$ Ela tem sido contemplada da perspectiva diacrônica, investigandose os usos fontes dos itens gramaticais e as trajetórias das mudanças que os afetam, através do recorte de diferentes períodos de tempo e da comparação dos estados de língua encontrados em cada um desses períodos. Para Heine (2003, p. 598), a gramaticalização é

um campo diacrônico no sentido exato: não apenas permite reconstruções históricas como também torna possível, dentro de limites, prever desenvolvimentos que acontecerão futuramente.

Todavia, em alguns casos, tem sido necessário recorrer à perspectiva sincrônica, analisando-se fontes e trajetórias com base em dados de uma só época, procedimento adotado em especial quando registros da forma a ser investigada são encontrados apenas em amostras de fala ou de escrita contemporâneas, tornando impossível, portanto, voltar o olhar ao passado como fonte de informações. Um dos efeitos da gramaticalização é a persistência (HOPPER, 1991), isto é, o fato de que nuanças semântico-pragmáticas e mesmo morfossintáticas de uma construção fonte lexical são passíveis de serem retidas por bastante tempo por suas herdeiras gramaticais. Essa retenção de especificidades de usos anteriores permite a recuperação da história do material gramatical, revelando não somente informações acerca de sua fonte, mas também acerca dos estágios ao longo de seu percurso de desenvolvimento. Assim, mesmo na ausência de evidência direta ou no caso de evidências esparsas acerca da fonte e das trajetórias seguidas por uma dada forma, estas podem ser divisadas através dos múltiplos usos atualmente dados à forma, entendidos como estágios de possíveis percursos de gramaticalização. Nas palavras de Givón (1979, p. 83): "[...] os vestígios da mudança lingüística estão dispersos, como relíquias de outrora, ao longo da paisagem sincrônica".

Essa linha de investigação sincrônica adota a concepção metodológica de que existe uma tendência de isomorfismo entre o desenvolvimento diacrônico do processo de extensão funcional de

\footnotetext{
${ }^{2}$ Estudos formalistas também se voltam ao fenômeno da gramaticalização, como Roberts (1993) e Roberts e Roussou (1999).
} 
um certo item e as relações sincrônicas entre as diferentes funções desempenhadas por ele. Contudo, qualquer hipótese relativa a emparelhamentos presente-passado deve ser testada por meio de indícios provindos de fontes variadas tomados como complementares, pois, segundo Craig (1991), é raro mapearmos todos os elos de uma cadeia de gramaticalização em textos referentes a um único período de tempo, mas elos perdidos podem aparecer em textos de outro período.

Portanto, o melhor caminho parece ser aquele seguido pelos estudos que adotam uma perspectiva mais ampla, não apenas sincrônica ou diacrônica, mas pancrônica, ${ }^{3}$ postura natural quando se entende a gramaticalização como um processo sempre em andamento, o que impossibilita o recorte estático de períodos de tempo - eles possuem fronteiras indistintas, não podendo ser caracterizados como fatias discretas e isoladas. A perspectiva pancrônica exige que se busquem vestígios em amostras de fala e escrita de diferentes épocas e que se some todas as evidências obtidas para que se consiga traçar os passos da trajetória de gramaticalização de uma forma.

Neste artigo, é de uma perspectiva pancrônica, voltada para o ontem e para o hoje, que abordo a gramaticalização da forma daí, que, a partir de funções dêiticas espaciais, passou a desempenhar funções vinculadas à articulação entre partes do discurso de proporções variadas, tornando-se um conector. ${ }^{4}$ Utilizo dados extraídos de textos orais e escritos de diferentes períodos da língua portuguesa, tomando complementarmente informações provindas do presente e do passado para buscar indícios mais refinados acerca das fontes e dos percursos percorridos por daí, e para obter evidências da atuação, em seus processos de gramaticalização, de mecanismos de mudança de natureza cognitivo-comunicativa.

As próximas seções estão assim organizadas: 1) descrição de quatro mecanismos de mudança: metáfora, metonímia, reanálise e analogia; 2) relato dos procedimentos metodológicos seguidos no decorrer da investigação; 3) análise dos indícios das trajetórias de gramaticalização percorridas por dai em direção ao emprego como conector; 4)

${ }^{3}$ Já apontada por Saussure, no início do século XX, como uma das possibilidades de abordagem à língua.

${ }^{4}$ Optei pelo termo conector entre outros possíveis (por exemplo, conectivo ou conjunção). 
discussão do estatuto gramatical de algumas das funções desempenhadas por daí. O texto é finalizado com as considerações finais e as referências bibliográficas.

\section{Mecanismos de Mudança}

Subjacente à mudança lingüística, está a atuação de processos cognitivos que interagem com condições externas relativas às situações de troca lingüística. ${ }^{5}$ Tais processos são representados, nos estudos de gramaticalização, por mecanismos diversos, dentre os quais recebem maior destaque os quatro descritos a seguir: (a) extensão metafórica, (b) extensão metonímica, (c) reanálise e (d) analogia. Esses mecanismos operam no uso cotidiano da língua, quando os falantes e ouvintes negociam e adaptam funções e formas para levar adiante a troca comunicativa, o que permite que a língua escorregue e mude, alterando-se padrões gramaticais e sua contraparte mental.

A) Metáfora: Uma determinada forma passa a ser usada na expressão de um novo conceito através de um processo pelo qual dois conceitos diferentes são metaforicamente igualados, via similaridade de percepção de sentidos, e a forma que é usada em referência a um deles - o mais concreto - é estendida para se referir também ao outro - o mais abstrato. Assim, a experiência não física é compreendida em termos da experiência física, o tempo em termos de espaço, a causa em termos de tempo, as relações abstratas em termos de processos físicos ou relações espaciais. Um caso é o do desenvolvimento, no inglês, de be going to de indicação direcional - como em (i) Henry is going to town - à indicação de futuro - como em (ii) The rain is going to come. Segundo Heine et al. (1991), a transição da expressão de ação verbal em (i) para a expressão de tempo futuro em (ii) é metafórica, pois envolve uma transferência de um domínio a outro: o verbo go, denotando um movimento espacial, portanto, uma ação física concreta, é usado como um veículo metafórico para se referir ao domínio mais abstrato do tempo dêitico, uma noção gramatical.

\footnotetext{
${ }^{5}$ As situações de interação lingüística não acontecem independentemente do que está na mente de cada um dos interlocutores, e o que está na mente, por sua vez, é influenciado pelo que acontece no contexto da interação (cf. HUTCHINS, 1995; TOMASELLO, 1998).
} 
B) Metonímia: A metonímia envolve a especificação de um significado em termos de outro que está presente no contexto, mesmo que na forma de inferência, isto é, representa uma transferência através de contigüidade. Um subtipo é a inferência por pressão de informatividade, baseada em uma importante característica da comunicação, a habilidade de fazer inferências: o falante deve ser capaz de julgar que detalhes o ouvinte pode suprir por conta própria e formular seus enunciados de acordo, e o ouvinte precisa completar em sua interpretação os detalhes não fornecidos pelo falante, inferindo tanto quanto possível acerca do que este lhe diz. Quando o mesmo padrão de inferências ocorre freqüentemente com uma forma particular, essas inferências podem ser habitualizadas, tornando-se parte do conjunto de significados tipicamente exibidos pela forma. O significado novo tende a ser de natureza mais abstrata que àquele do qual foi pressionado a derivar. Retomemos aqui o caso de be going to comentado por Heine et al. (1991):

(i) Henry is going to town.

(ii) Are you going to the library?

(iii) No, I am going to eat.

(iv) I am going to do my very best to make you happy.

(v) The rain is going to come.

As sentenças de (i) a (v) sugerem que, entre o emprego de be going to para denotar ação verbal e para codificar futuro, há um contínuo - ou cadeia - de nuanças conceituais minimamente diferenciadas. Por exemplo, em (iii), que é uma resposta a (ii), o sentido primeiro de be going to parece ser intenção, com um sentido secundário de predição, mas ainda preservando traços do movimento espacial presente em (i) e (ii). O significado de (iv) parece similar ao de (iii), mas não há mais um sentido espacial. Finalmente, em (v), deixa de haver intenção, sendo o único sentido de be going to a predição. Para Heine et al. (op. cit.), o processo cognitivo que direciona as formas à gramática possui duas perspectivas: uma discreta e psicológica por natureza, que sugere uma análise em termos de metáfora; outra contínua e pragmática, altamente dependente do contexto e exibindo estrutura metonímica. A compatibilidade entre tais atividades cognitivas divergentes parece resultar de uma interação entre o comportamento taxionômicoconceitual e as estratégias pragmático-discursivas. 
C) Reanálise: Conforme Harris e Campbell (1995), a reanálise modifica a estrutura subjacente das construções lingüísticas (sintagmas, orações), envolvendo reorganização e mudança de regras lineares, sintagmáticas, freqüentemente locais. É a ambigüidade de algumas construções em certos contextos que induz os usuários da língua a interpretar a cadeia input de modo diverso, estabelecendo assim novos "cortes", isto é, novas relações entre as palavras. Seguidamente, o recorte diferenciado do material lingüístico implica mudança categorial, isto é, a transferência de um âmbito a outro (por exemplo, de verbo à preposição, de preposição à conjunção, de adjetivo a advérbio, etc). As transformações resultantes da reanálise não são diretamente observáveis, pois não levam a nenhuma modificação imediata ou intrínseca na manifestação de superfície da construção reanalisada.

D) Analogia: A analogia é responsável por re-arranjos paradigmáticos, ocasionando a generalização de uma forma para contextos lingüísticos diversos, pertinentes à sua nova função gramatical. A analogia faz com que se tornem mais evidentes as alterações nos padrões morfossintáticos que resultaram da reanálise, cuja ação pode não ser diretamente observável. Tomando o exemplo do desenvolvimento de be going to de sintagma direcional a futuro, temos, no estágio inicial, uma construção progressiva com um verbo lexical de direção complementada por uma oração sinalizando finalidade (como em She [is going] to visit Bill). Depois, como resultado da reanálise, a construção be going to se torna auxiliar de futuro, inicialmente especializada para acompanhar verbos lexicais de atividade (como em She [is going to] visit Bill). O terceiro estágio é o da extensão analógica do auxiliar de futuro de verbos de atividade para todas as classes verbais, inclusive os estativos (como em She [is going to] like Bill). A analogia leva a aumento de freqüência: quanto mais contextos de uso possíveis, mais o item tende a aparecer. Em outras palavras, o aumento de types provoca o aumento de tokens, o que contribui para tornar a mudança visível.

As atuações da metáfora, da metonímia, da reanálise e da analogia são compatíveis, pois cada passo dado pelas formas gramaticais pode desencadear uma série de modificações: acontecem transferências de um domínio funcional a outro (metáfora); as inferências contextuais tornam-se mais e mais rotinizadas (metonímia); são re- 
elaboradas as relações sintagmáticas entre as porções da língua (reanálise); as formas são ampliadas para um número maior de contextos de uso (analogia).

Constantemente, itens gramaticais são criados ou desaparecem ao longo de trajetórias de mudança translingüisticamente semelhantes, o que dá origem à boa parte das similaridades entre as línguas. $\mathrm{O}$ caráter universal dessas trajetórias é atribuído à ação dos mecanismos cognitivo-comunicativos descritos acima, comuns à humanidade como um todo.

Todavia, a gramaticalização não acontece abrupta e repentinamente como se as formas saltassem de uma categoria lingüística à outra, mas sim se caracteriza por um desenrolar lento e gradual, envolvendo estágios de alternância do tipo $\mathrm{A}>\mathrm{A} / \mathrm{B}>\mathrm{B}$ (HOPPER, 1998), em que emergem usos novos que são análogos mas não idênticos aos pré-existentes. Ou seja, a cada etapa sucessiva, as formas diferem minimamente em função. Segue daí que a mudança é quase imperceptível aos usuários da língua. Por conseguinte, é mais apropriado postular trajetórias de mudança em forma de cadeias de gramaticalização do que propor estágios discretos de alterações. Cadeias de gramaticalização são padrões de relação entre usos precedentes e subseqüentes de um item lingüístico que podem ser mapeados sincrônica ou diacronicamente e organizados ao longo de uma linha imaginária. Em tal linha, há pontos focais necessariamente arbitrários, já que ocorre a segmentação de uma trajetória de mudança contínua em unidades discretas, mas é previsto que, entre quaisquer dois pontos, há usos com traços de um e de outro, isto é, usos indistintos, ambíguos, de difícil categorização.

\section{Procedimentos Metodológicos}

$\mathrm{Na}$ busca de vestígios da extensão funcional de dai ao longo do tempo, considerei uma gama de informações:

(i) Traços semântico-pragmáticos comuns a duas ou mais das funções codificadas atualmente ou no passado por daí; (ii) Relações de abstração entre tais funções, com base em trajetórias de mudança universais como as propostas por Heine et al. (1991); 
(iii) Evidências da ocorrência de generalização de uso: quanto mais disseminada em diversos contextos lingüísticos está uma forma, mais avançada está em sua trajetória de gramaticalização;

(iv) Aspectos sintáticos, principalmente aqueles referentes às relações manifestadas entre daíe demais itens lingüísticos circundantes - indícios de alterações nesse plano são indícios da ação da reanálise;

(v) Dados ambiguos e 'entres' de diversos tipos, passíveis de representarem estágios intermediários de mudança. Como a gramaticalização não acontece abrupta e repentinamente, mas sim gradualmente, a cada etapa uma forma pode diferir minimamente em função. Conseqüentemente, as alterações são de natureza incremental, deixando usos ambíguos como indícios que auxiliam a recuperar a trajetória de irradiação funcional das formas.

Analisei dados de fala do final do século XX, extraídos de 48 entrevistas feitas com florianopolitanos nativos, obtidas junto ao Banco de Dados VARSUL/UFSC (Variação Lingüística Urbana da Região Sul). São entrevistas de cerca de uma hora de duração, consideradas em sua integralidade. Os entrevistados distinguem-se quanto aos traços sociais gênero, idade ( 09 a 12, 15 a 21, 25 a 45, mais de 50 anos) e nivel de escolarização ( $4^{\mathrm{a}}$ ou $5^{\mathrm{a}}$ séries do ensino fundamental; $8^{\mathrm{a}}$ série do ensino fundamental; $3^{\circ}$ ano do ensino médio).

Como havia a necessidade de retroceder para períodos de tempo distantes, tive de a recorrer textos de modalidade escrita. Então, selecionei cerca de quarenta obras de vários gêneros, escritas em língua portuguesa dos séculos XIII a XX, que apresentassem traços de aproximação com a fala. A eleição dessas obras pautou-se nos seguintes critérios: (i) textos referentes ao período arcaico e ao início do período moderno do português, cuja escrita tende a aproximar-se da fala, pois nessa época ainda não tinham sido especificadas regras gramaticais e de concordância rígidas (cf. SILVA, 1991); (ii) para períodos de tempo posteriores, textos como peças teatrais e romances cujos autores pretendessem imitar a fala na voz de suas personagens; (iii) textos ligados a movimentos literários voltados à defesa da língua 
'brasileira', caso, por exemplo, do modernismo do início do século $\mathrm{XX}$, em que era comum o acréscimo de marcas da oralidade à escrita.

Todavia, a freqüência de aparecimento de daí, seja como dêitico seja como anafórico, é bastante baixa nos diversos textos escritos consultados, com exceção da edição de 1940 do romance As vinhas da ira, tradução brasileira de The grapes of wrath, de John Steinbeck. Além disso, não encontrei, nesses textos, nenhum dado de daí no papel de conector. Dá-se com ele o mesmo que ocorre com aí, outra forma que migrou, no português brasileiro, de usos dêticos a usos conectivos: Braga (2002, p. 07) aponta como "dificuldade básica inerente aos estudos voltados para a trajetória de aí [...] a inexistência de material diacrônico que fundamentasse a análise." A falta de dados referentes ao emprego de daí na conexão entre segmentos do discurso dificulta a re-constituição histórica dos caminhos de mudança percorridos por tal forma, restando a tarefa de preencher lacunas à abundância de ocorrências encontradas na sincronia mais recente, representada pela fala registrada nas entrevistas pertencentes ao Banco de Dados VARSUL.

\section{Espaço $\rightarrow$ (tempo) $\rightarrow$ texto}

Heine et al. (1991) apontam que as candidatas principais à gramaticalização são, quanto ao significado, as formas que se referem a universais da experiência humana, representando aspectos concretos, básicos e gerais ${ }^{6}$ para a orientação no meio ambiente. Tais propriedades as tornam ampliáveis para a referência a conceitos menos concretos. Destacam-se, entre outros, os itens lexicais que designam partes do corpo, os verbos dinâmicos, os quantificadores e os demonstrativos básicos, especialmente indicadores de espaço. ${ }^{7}$ Esse é o caso de daí, uma construção composta pela contração da preposição de com o dêitico espacial $a$, que apareceu, com as variações $d y, d i$, $d j$, somente a

\footnotetext{
${ }^{6}$ Por exemplo, tendem a ser gramaticalizados não verbos de movimento mais específico como caminhar ou nadar, mas verbos de movimento mais geral como ir e vir (HEINE et al., 1991).

${ }^{7}$ São agrupados sob o rótulo demonstrativo itens ou construções que possuem em comum a propriedade de apontarpara algo (pessoa, objeto, espaço, tempo, etc), seja dêitica ou anaforicamente.
} 
partir do século XIV. $A i$, por sua vez, provém do arcaico $i$ (ou hi), que se aglutinou a $a$, um prefixo de valor intensificador ou enfático. Já $i$ é proveniente do ibilatino, termo multifuncional, podendo significar nesse lugar ou nesse momento. ${ }^{8}$

De todos os usos de daí que encontrei nos textos dos séculos XIII ao XX e nas entrevistas florianopolitanas, o que apresenta os traços mais concretos, mais próximos das experiências humanas com o mundo circundante, é o dêitico espacial. Como suas funções mais remotas envolvem papéis voltados à indicação espacial, é possível considerar que daí sofreu gramaticalização segundo um percurso universal tipicamente envolvido na emergência de conectores: espaço $>$ (tempo) > texto (HEINE et al., 1991). Esse percurso de mudança sintetiza a trajetória de acordo com a qual elementos indicadores de espaço externo passam a ser utilizados como indicadores temporais e, por fim, como conectores, sendo possível um percurso da indicação de espaço externo diretamente para a conexão entre partes do discurso. É previsto aí um movimento rumo a níveis cada vez mais gramaticais, atribuído aos mecanismos cognitivo-comunicativos universais pelos quais os usuários da língua tendem a guiar em uma mesma direção rumo à abstração, à generalização - os novos usos que dão às velhas formas. A transferência de uma forma de uma função à outra não é automática, sendo previstos estágios em que o estatuto da função desempenhada é indefinido, em razão da sobreposição entre o uso mais antigo e o uso mais recente, o que ocasiona situações de ambigüidade do tipo $A / B$ : espaço/tempo; espaço/conexão textual, etc.

Nas seções a seguir, apresento com mais detalhes o trajeto que deve ter sido seguido por daí, destacando: 1) a migração do âmbito dêitico ao âmbito anafórico, 2) a passagem do plano da referência anafórica ao plano da conexão entre partes do discurso.

\subsection{Dêixis $\rightarrow$ anáfora}

Os dêiticos são palavras ou expressões usadas para apontar, no contexto extra-lingüístico, um indivíduo, objeto ou lugar,

\footnotetext{
${ }^{8}$ Os dicionários etimológicos dos quais obtive as informações acerca da origem
} de daí são: Cunha, 1991; Nascentes, s/d; Silveira Bueno, 1965. 
e introduzi-lo no discurso, relacionando o enunciado a suas coordenadas pessoais, espaciais ou temporais. Laury (1997) afirma que eles têm conexão real com o que significam, pois, como se fossem dedos, apontam para algo presente no contexto no momento mesmo da interação. Por essa razão, seu uso é freqüentemente acompanhado por um gesto indicativo. Como dêitico espacial, daí sinaliza movimento de afastamento do espaço em que o ouvinte está ou de um lugar próximo ao ouvinte. Leva a cabo, portanto, uma indicação de natureza direcional, de caráter ablativo (algo ou alguém sai do exterior de um lugar) ou elativo (algo ou alguém sai do interior de um lugar), para o que contribui a preposição de da construção dai - algo ou alguém sai $d e+a i=$ algo ou alguém sai de algum lugar próximo ao ouvinte (CASTILHO, 1997; COSTA, 1999).

(1) Tu vai ver - disse. - Fica aí até chegar o carro e tu vai ver. Talvez seja o Willy Feeley e o Willy agora é ajudante do "sheriff". É autoridade. Que é que tu 'tá fazendo aquí? Aquí é proibido - vai dizer o Willy. Bem, tu sabe, o Willy foi sempre um sujeito metido a besta. Tu diz: que é que tu tem com isso? Aí o Willy fica danado e diz: Tu sai daí, ou senão eu te levo comigo. Tu não vai deixar que êle grite contigo, e aí 'tá armado o barulho. (STEINBECK, 1940, p. 60)

(2) E a cova ia ficando mais e mais profunda, pois que êles trabalhavam incessante e vigorosamente. Quando já estava numa cova retangular que lhe vinha até a altura dos ombros, Tom disse: - Mais fundo ainda, pai? Tem que ser bastante fundo. Alguns pés mais. Tu sai dai agora, Tom. Vai escrever aquele papel que falámos. Tom içou-se da cova e Noah tomou o lugar dêle. (STEINBECK, 1940, p. 149)

(3) Êles foram, mesmo, ou então a mãe morreu. - Falou, e apontou para a porta do cercado. - Se minha mãe estivesse aquí, essa porta estaria fechada e com cadeado. Minha mãe sempre fechava essa porta com cadeado, desde que o porco fugiu dai e correu até a casa dos Jacobs. (STEINBECK, 1940, p. 43) 
(4) É igual a um vôlei mesmo, a gente saca, aí tem que levantar. Se sacar fo- assim dentro de um lugar aí, sai daí, (hes) se sacar dentro da área, sai. (RR/ FLP04C:13) ${ }^{9}$

Em (1) e (2), daí dêitico espacial aponta para o lugar em que o ouvinte está e do qual este recebeu ordens de se deslocar. Em (3), temos uma situação ambígua $A / B$ em que o local indicado está próximo de uma das personagens, mas também foi referido previamente (no trecho em negrito), e daí pode ser entendido como dêitico, apontando para o mundo exterior, ou como anafórico, apontando para o discurso anterior. Contextos desse tipo, em que ambas as leituras são possíveis, podem ter pressionado a passagem de dai da dêixis espacial para a anáfora espacial. Em (4), dai recupera uma referência espacial mencionada previamente (dentro de um lugar aì), assumindo, portanto, um papel indubitavelmente anafórico - a quadra de voleibol a que o falante se refere não se encontra nas proximidades do local em que ele e o entrevistador estão.

É possível definir a anáfora como um apontamento para trás que lança o foco das atenções sobre um ponto anterior do discurso do falante ou de seu interlocutor - seja lugar, seja tempo, seja outra informação qualquer -, como se fosse um gesto verbal apontando para algo dito previamente. Quando o subtipo de anáfora que ora nos interessa, a espacial, é utilizada, acontece um movimento de recuperação de uma referência espacial antecedente específica. Como anafórico, dai mantém seu papel ligado à indicação espacial ablativa ou elativa, mas as relações estabelecidas são re-analisadas: deixa de haver sinalização para o âmbito externo do discurso, e passa a haver sinalização para o âmbito interno, surgindo uma relação de co-referência entre dai e a expressão que primeiro referiu o espaço em causa. Isso acontece nos seguintes termos: dai aponta para um elemento do discurso prévio, constituindo com ele

\footnotetext{
${ }^{9}$ O código que segue o trecho da entrevista a identifica. Por exemplo, (RR/ FLP04C:13) = informante RR, natural de Florianópolis (FLP), entrevista número 04 , linha 13. Nos casos em que há uma letra após o número da entrevista, podemos ter ou $\mathrm{J}=$ informante de 15 a 21 anos ou $\mathrm{C}=$ informante de 09 a 12 anos.
} 
um vínculo de co-referência, pois esse elemento faz referência a um lugar e dai adota para si o mesmo referente.

A extensão funcional dêixis espacial $>$ anáfora espacial sofrida por dai é corriqueira em muitas línguas (HEINE et al. 1991; FILLMORE, 1982), e implica a passagem de um item de uma função relacionada a apontamento a espaço circundante no mundo real para uma função ligada à organização interna do discurso. Contextos caracterizados por certa indeterminação quanto à natureza do apontamento feito por dai - se dêitico ou anafórico (cf. (3)) representaram excelentes pontos de partida para que ele estendesse seus tentáculos de uma função à outra.

A metáfora está envolvida em tais desdobramentos funcionais. $\mathrm{O}$ apontamento para um espaço presente no contexto em que a conversa ocorre pode ser considerado de natureza concreta em razão do vínculo estabelecido entre o discurso e o mundo exterior a ele. Tal apontamento é tomado como similar àquele que se dirige para um espaço anteriormente mencionado, mais abstrato por envolver relações internas ao discurso. Essas similaridades permitem que daí seja estendido do domínio dêitico ao anafórico, realizando neste, à semelhança de seus encargos no plano da dêixis, mapeamentos espaciais, mas, agora, sobre dimensões textuais. Ocorre, empregando os termos de Frajzyngier (1991), uma transferência de um domínio de re a um domínio de dicto, passando a organização espacial do mundo concreto (da experiência sensório-motora, dos objetos visíveis e tangíveis) a ser utilizada para organizar o universo mais complexo do texto, das organizações e relações interiores ao dizer. Como é típico no processo de transição de uma função a outra, há estágios de ambigüidade (como o exemplificado em (3)).

Não é possível desprezar-se, porém, a hipótese de que pequenas transferências metonímicas estejam subjacentes às modificações mais amplas de natureza metafórica. Pressões on-line para a absorção de inferências que se manifestam em contextos particulares de uso de dai (situações do tipo $A / B$ ) podem ser o ponto de partida para a extensão funcional da unidade sob análise em seus diferentes estágios de mudança. Como afirmam Heine et al. (1991), metáfora e metonímia coexistem como "parte e parcela" no processo de gramaticalização. As alterações funcionais sofridas por daí também implicam a atuação da reanálise. Como dêitico, daí vincula-se ao mundo externo e, como 
anafórico, vincula-se a um ponto do discurso já mencionado, dando origem a uma relação de co-referência não existente quando do apontamento dêitico espacial, isto é, as relações entre as formas lingüísticas envolvidas são recortadas e interpretadas de modo distinto pelos usuários da língua.

Não mapeei ocorrências de daí codificando indicação temporal dêitica ou anafórica, ${ }^{10} \mathrm{o}$ que representaria a segunda etapa da trajetória de mudança tipicamente envolvida na emergência de novos conectores, espaço $>$ (tempo) $>$ texto. É possível, portanto, que ele tenha migrado diretamente de seus empregos como anafórico espacial para papéis na organização textual, pegando um atalho na trajetória em questão, em um movimento já previsto por Heine et al. (1991). Todavia, uma outra possibilidade referendada pelos dados obtidos é que daí tenha adentrado o plano da conexão discursiva não através de seus usos como item anafórico espacial, e sim via um uso híbrido entre anafórico discursivo e conector, em que a forma, ao apontar não para um lugar mas para uma informação prévia, acaba exibindo uma das nuanças de significado tipicamente vinculadas à conexão entre partes do discurso, a de introdução de efeito (conseqüência ou conclusão). Encontrado em textos do início do século, tal uso é freqüente ainda hoje, aparecendo inclusive na fala de Florianópolis:

(5) I: Agora, A., o fechamento sempre existiu. Porque eu digo pelo casamento (inint) tanto a $\mathrm{N}$.

F: A irmã do meu avô.

I: A irmã do teu avô. Tanto a N. como a mamãe, que era a irmã, elas foram mais marcadas.

F: Ah, isso foi, é. Discriminação.

I: Aceitação- aceitação da família. Mamãe sempre dizia:

"Vocês casem (inint)."

\footnotetext{
${ }^{10}$ Não houve dados de dai atuando de modo isolado como dêitico ou anafórico temporal. Os únicos casos ligados a tempo que encontrei foram expressões anafóricas cristalizadas como dai em diante, daí pra cá, que possuem empregos espaciais e temporais, mas não parecem participar dos desenvolvimentos de daírumo à conexão textual, já que ele, como conector, aparece sem complementos como em diante.
} 
F: É daí- daí também esse entroncamento que houve, né? na família. Daí veio isso. Eles não procuravam pessoas assim estranhas, porque as que tinham procurado tinham levado na cabeça. Então eles procuravam se entrelaçar, né? dentro do próprio tronco. (AL/FLP22:769)

(6) Há uma outra face do Marechal Floriano que muito explica os seus movimentos, atos e gestos. Era o seu amor à família, um amor entranhado, alguma cousa de patriarcal, de antigo que já se vai esvaindo com a marcha da civilização. / Em virtude dos insucessos na exploração agrícola de duas das suas propriedades, a sua situação particular era precária, e não queria morrer sem deixar à família as suas propriedades agrícolas desoneradas do peso das divídas. / Honesto e probo como era, a única esperança que lhe restava, repousava nas economias sobre os seus ordenados. Daí lhe veio essa dubiedade, esse jogo com pau de dous bicos, jogo indispensável para conservar os rendosos lugares que teve e o fez atarraxar-se tenazmente à presidência da República. (LIMA BARRETO, 1915, p. 115)

(7) As proposições são membros do periodo, assim como os termos logicos são membros da proposição; estes se combinam para formar a proposição, e aquellas para formarem o periodo. $\mathrm{Na}$ combinação destas intervem a conjuncção, e na daquelles a preposição. Dabi certa analogia de funcção das duas classes de particulas. (PEREIRA, 1923, p. 563)

Nesse uso híbrido entre anáfora discursiva e sinalização de efeito, temos uma construção composta por dai e pelo verbo vir, que pode estar elíptico. Em (5), tanto daí quanto daí veio apontam para diversas informações dadas anteriormente, relativas à discriminação sofrida pelos membros da família que se casavam com pessoas de fora. Tais informações são convertidas na causa da informação introduzida por dai: daí também esse entroncamento que houve, né? na familia. Daí veio isso. Ou seja, como havia fortes restrições ao casamento com estranhos, ocorreu um 'entroncamento' na família, pois a maioria passou 
a optar por casar com parentes. Em (6), a causa apontada anaforicamente pela construção daí veio - o amor à família e insucessos nos negócios - teve a conseqüência introduzida pela mesma construção --- atitudes dúbias visando à preservação do cargo de presidente da República. Em (7), dai aponta para o papel da preposição e da conjunção na combinação dos termos lógicos e das proposições como sendo responsável por certa analogia funcional entre essas classes de palavras.

A construção dai $(+$ vir), que pode ser denominada "anafórica discursiva introdutora de efeito", tem sua origem nos usos anafóricos espaciais de daí, em que ele aponta para um local previamente referido. À semelhança de sua fonte, a construção dai (+ vir) aponta também para algo previamente referido, mas não um lugar e sim uma ou mais informações e, ao mesmo tempo, direciona o discurso rumo à sua continuidade, ao permitir a inferência de que a informação introduzida por si representa uma conseqüência das informações prévias para as quais aponta.

No processo de migração funcional, ocorre uma transferência metafórica do plano da indicação anafórica espacial para o plano da indicação anafórica discursiva, responsável pelo apontamento para informações quaisquer previamente dadas, não especificamente espaciais ou temporais. Daí deixa de apontar para locais de onde vem algo ou alguém e passa a apontar para causas de onde vêm conseqüências. Como tipicamente ocorre quando a metáfora está em jogo, um conceito mais complexo torna-se mais facilmente compreendido apelando-se para formas costumeiramente vinculadas a conceitos mais concretos: o uso do dai permite apresentar causas como lugares de onde vêm conseqüências, fornecendo às primeiras um traço de concretude. Daí continua manifestando indicação direcional ablativa/ elativa - ou seja, a preposição de ainda tem um papel atuante: a conseqüência vem de algum 'lugar' (a sua causa).

\subsection{Anáfora $\rightarrow$ conexão}

Ao ser utilizado como sinalizador de movimento anafórico discursivo que deixa vir à tona nuanças de conseqüência, daí inicia seu processo de mudança rumo ao papel de conector. Em certas situações $A / B$, o interlocutor é posto em dúvida acerca da presença do traço de apontamento direcional, o que impulsiona a transmutação 
funcional de daí. Em (8), por exemplo, dai pode estar apontando para a informação a mulher não tem, nem pai nem mãe, não tem autoridade sobre os filhos como o lugar de onde advém a conseqüência vai se formando essa geraçãozinha cada vez mais- mais (hes) perversa, né? Neste caso, o traço direcional ablativo/elativo é percebido (e está em jogo a construção dai $(+$ vir $)=$ dai vai se formando...) e temos o uso híbrido de daí (anáfora discursiva/ introdução de efeito). Todavia, daí, em (8), pode ser entendido como codificando apenas introdução de efeito, caso em que poderia ser substituído por conectores comumente empregados na expressão de conseqüência ou conclusão, como então, por isso e mesmo $e$.

(8) A mulher não tem, nem pai nem mãe, não tem autoridade sobre os filhos. Daí vai se formando essa geraçãozinha cada vez mais- mais (hes) perversa, né? perversa, perversidade (AL/FLP22:118).

Temos aqui mais uma atuação da reanálise, recortando de modos distintos as relações entre dai e e as formas circundantes a cada etapa de mudança: o deslocamento o plano da conexão discursiva libera dai da relação de co-referência com um item específico do universo discursivo anterior, e a forma passa a assumir o papel de conector. Daí é re-interpretado de modo que de deixa de ter papel significativo como indicador direcional, sendo absorvido como parte indissociável de uma só unidade. Ou seja, ao se ver livre do apontamento ablativo/elativo, daí torna-se um conector introdutor de efeito e a existência de uma preposição na construção deixa de ser percebida pelos usuários da língua.

(9) Quando ela está fazendo alguma coisa e a gente está brincando ela se irrita com o barulho, dai ela dá tapa em nós, dai ela apanha também do pai, não vai deixar a gente apanhar de graça. (AO/FLP11C:06)

(10) Dada a facilidade de se encontrar outra, ou ela encontrar outro, é tão grande que num piscar de olhos as (hes) coisas se invertem. Daía família fica em segundo plano. (MA/FLP14:454) 
Para um certo falante, a relação entre duas informações particulares pode ser claramente de causa-conseqüência, mas seu ouvinte pode entender essa relação de outro modo, o que representa um gatilho não só para situações de sobreposição de significado e ambigüidade, mas também para que novas possibilidades de uso emerjam. Assim é que, tendo chegado no plano da conexão entre partes do discurso através da indicação de efeito, daí teve seu emprego generalizado para a codificação de mais algumas funções vinculadas ao mesmo plano, a seqüenciação temporal, a seqüenciação textual, a adversão e, talvez, a explicação.

É difícil especificar se daí passou por essa trajetória de ampliação funcional seguindo por um percurso do tipo introdução de efeito $>$ seqüenciação temporal $>$ seqüenciação textual $>$ adversão, ou qualquer outra combinação possível, uma vez que não foram encontrados indícios para a estipulação de etapas de mudança mais detalhadas. O fato é que, dado seu aparecimento constante em contextos de indicação de conseqüência/conclusão, daí acaba escalado para cobrir um maior número de funções pertinentes ao âmbito da conexão de partes do discurso, através da incorporação de traços de significado presentes em contextos determinados. É possível ainda que a ampliação do leque de funções de dai no plano da conexão tenha sido influenciada pelos usos dados a outros conectores no português brasileiro, como $e$, aí então, que sinalizam as mesmas ou similares funções. Diferentemente da passagem de daí de anafórico para conector, sua migração para as várias funções no plano da conexão do discurso não acarreta mudança de categoria, pois não ocorre transferência de uma classe gramatical para outra, dispensando a ação da reanálise.

Como seqüenciador temporal, dai coloca em evidência a ordenação temporal cronológica dos eventos narrados, indicando que o evento seguinte ocorre depois que o anterior se conclui:

(11) A sereia Ariel foi lá em cima pra ver o que que era aquelas coisas lá... luminosas, que eram os fogos de artifícios, Daí ela- daí ela viu o homem que estava no- no barco, né? daí ela se apaixonou por ele, dai ela foi na casa da bruxa do mar e pediu pra transformar ela em humana, com as pernas, dai ela foi pra terra, mas ela ficou assim sem voz. (JL/FLP09C:05) 
(12) Faz a massa, espera esfriar. Daí faz uma bolinha, depois recheia com catupiri, fecha, deixa crescer. (LE/ FLP05J:1013)

Como seqüenciador textual, daí destaca a relação de sucessão discursiva existente entre informações anteriores e posteriores, deixando transparecer que a informação que introduz tem a ver com as demais, por fazerem parte de um mesmo assunto:

(13) Só que tem que tomar cuidado por causa que ela é um gato de carne, né? daí quando vai pra rua os cachorros querem comer ela, né? daí a minha mãe tem um cachorro, e ele avança nesse gato, nessa gata, quando o gato fica- vai pra casa os cachorros só ficam olhando, né? (KA/FLP08C:127)

(14) Ah, eu acho que aqui tem muita gente olha: que joga coisa no chão, né? que inclusive até ontem passou no jornal- no jornal do almoço (hes) que muita gente, né? eles- o- a preferência das pessoas é jogar no chão, né? Daí mostrou assim a lixeira, do lado assim, a lixeira e do lado um monte de lata, papel, tudo jogado no chão, e a lixeira ali do lado. (DE/ FLP06J:714)

Como adversativo, dai exibe um contraste, uma antítese entre as informações conectadas:

(15) Meu pai não é nem um pouco católico, entendeu? Quer dizer, ele era, mas não era praticante de todo dia, né? essa história toda. Aí eu não- não- não ia. Daí, de um tempo pra cá, eu comecei a me interessar, né? conhecer a palavra, em ir pra igreja e conhecer a Jesus, o Cristo. (EV/FLP08J:933)

Também é possível apontar como função que pode vir a ser adquirida por daí, como conector, a explicação, geralmente marcada por porque. Em (16), temos favorecida a leitura de introdução de efeito, mas o contexto também deixa transparecer uma leitura explicativa 
suave, como se a informação subseqüente estivesse fornecendo uma razão, uma justificativa para a informação precedente. A repetição em contextos desse tipo poderia levar daí a ser mais e mais relacionado à explicação, habitualizando-se como uma de suas formas de expressão.

(16) Porque se a gente não estudar, a gente não vai ser nada na vida, né? [vai ser]- a gente vai sofrer, cair pelas ruas, não tem nada pra fazer. Eu acho importante estudar, dai a gente pode trabalhar, dai pode fazer um monte de coisa, dançar. (RA/ FLP12C:19)

Um caso de função adquirida por dai a partir de usos conectivos é a marcação de hesitação. Nessa função, ele atua no âmbito do processamento da fala e da manutenção de turnos, como sinal de hesitação por parte do falante e para evitar o silêncio enquanto um novo trecho de fala é estruturado. Sua pronúncia costuma ser alongada. $\mathrm{O}$ uso de itens conectivos exibindo hesitação é bastante comum. Marcuschi (1999, p. 173), em um estudo sobre o fenômeno, aponta que, no corpus que analisou, o número de hesitações constituídas por conjunções representa 30\% do total de ocorrências, sendo as conjunções mais freqüentes nesse papel $e$ e que, seguindo-se mas, ou, como, daí, já, então, se. De acordo com o autor, as palavras funcionais, tais como conjunções e preposições, “[...] são as formas lingüísticas mais freqüentes como material lingüístico para constituir as hesitações”, as quais representam os sintomas de um processamento em curso. Um exemplo:

(17) Aí nós fomos lá, lá no reitor, daí- Aí ele passou já o cheque, (hes) aí fui no banco. (AN/FLP05:420)

Quanto aos estágios de mudança de dai posteriores à sua chegada no plano da conexão do discurso, temos situações de duas espécies: (i) usos mais enraizados e generalizados, como os do plano da introdução de efeito, da seqüenciação textual, etc, em que o item recorre, atualmente, na fala de vários indivíduos - um indício de rotinização gramatical efetivada ou em curso; (ii) usos portando nuanças inovadoras apenas suspeitas de representarem inovações em seu momento de gestação, como acontece com daí explicativo, que é pouco 
freqüente e aparece na fala de apenas dois dos informantes florianopolitanos entre os considerados para este estudo. Se a explicação será incorporada ao conjunto de funções desempenhadas por daí, só o tempo dirá...

\section{Uma Questão de Gramática}

Daí, via gramaticalização, move-se em direção a pólos cada vez mais gramaticais, passando da dêixis à anáfora e desta à conexão discursiva. No entanto, o ponto de partida de tais desenvolvimentos não é o léxico e sim, desde o início, a própria gramática. Com o intuito de lançar um olhar mais aprofundado sobre a natureza gramatical dessas funções, urge refletir sobre o papel do significado. Para tanto, diferencio, a seguir, significados gramaticais de significados lexicais, ressalvando, porém, que a fronteira entre ambos os níveis não revela demarcações rígidas, pois as palavras são manipuladas de modo criativo e variado pelos usuários da língua. Necessidades comunicativas on-line de se fazer entendido e de entender, de ser mais ou menos expressivo resultam em relações dinâmicas entre léxico e gramática: do léxico derivam constante e gradualmente inovações gramaticais.

Os significados lexicais fazem referência ou descrevem coisas do universo biossocial - entidades, ações, qualidades. Os nomes e os verbos costumam ser consideradas itens típicos do âmbito lexical. Os significados gramaticais atuam na organização dos itens lexicais no discurso: relacionam nomes (preposições), ligam partes do discurso (conjunções ou conectores), indicam se as entidades e participantes de um discurso já foram identificados ou não (pronomes e artigos), mostram se eles estão próximos do falante ou do ouvinte (demonstrativos), entre outras funções.

Os significados das formas lingüísticas são negociáveis, em maior ou menor extensão. Alguns significados, notadamente os lexicais, são relativamente estáveis e fixos a cada uso, enquanto outros, geralmente de natureza gramatical, dependem fortemente do contexto circundante para serem interpretados. Por essas características, são mais negociáveis quando da interação. A gramaticalização representa uma evolução de um estado de maior autonomia e estabilidade de significados para um estado de menor autonomia e maior instabilidade: à medida que os itens lexicais sofrem gramaticalização, emergem 
significados de natureza abstrata e genérica, mais adaptáveis a contextos de uso diversificados.

Os usos demonstrativos dêiticos e anafóricos de daí são gramaticais, por dependerem fortemente do contexto circundante para ser interpretados (contexto externo, no caso dos dêiticos, e informações anteriores, no caso dos anafóricos), assumindo novas feições a cada evento interacional. Estão, porém, em um plano menos gramatical que os conectores: Hopper e Traugott (1993) e Ramat (1998) afirmam que o desenvolvimento de dêiticos e de anafóricos em conectores, um fenômeno universal nas línguas, é um caso de aumento do grau de gramaticalização de itens já gramaticais que passam a servir para expressar a relação entre partes do discurso.

Cristofaro (1998) também assume posição similar, apontando que demonstrativos podem ser considerados menos gramaticais por se referirem a entidades individuais - pessoa, objeto, espaço ou tempo - num nível dêitico ou anafórico, ao passo que conectores significam relações mais abstratas, não apontando para uma entidade específica, e sim estabelecendo elos coesivos. No caso de daí, como seus usos dêiticos relacionam-se diretamente ao espaço exterior concreto - o domínio de re, ancorando nele o enunciado, estão a um passo aquém de seus usos anafóricos. Anáforas possuem um grau maior de abstração por ancorarem o enunciado em uma informação passada, a qual possui como referente um espaço ou um período de tempo. Elas atuam, portanto, na organização interna do texto - no domínio de dicto -, vinculando uma informação à outra, ao passo que os dêiticos vinculam uma informação ao contexto exterior da situação comunicativa, utilizando algo concreto do mundo como âncora para a informação. Em contraste, os usos conectivos de daí desempenham tarefas em níveis ainda mais gramaticais, pois estabelecem laços coesivos entre informações, deixando transparecer traços de significação relacionais como seqüenciação temporal, introdução de efeito, seqüenciação textual e adversão.

\section{Considerações Finais}

Neste estudo, em uma postura pancrônica, presente e passado foram tomados em conjunto para a busca de elos para a reconstituição dos aclives de mudança por que passou a forma dai desde 
os usos como dêitico espacial até os usos como conector. Foi possível traçar sua trajetória de mudança com base em informações de natureza diversa: (i) traços semânticos comuns a duas ou mais funções (indicação espacial, indicação de efeito, etc); (ii) relações de abstração entre essas funções (dêixis $>$ anáfora, anáfora $>$ conexão entre partes do discurso); (iii) generalização de uso (de anafórico espacial para anafórico discursivo, de introdução de efeito para seqüenciação temporal, seqüenciação textual e adversão); (iv) relações estabelecidas pelas formas (apontamento dêitico, apontamento anafórico, coesão entre partes do discurso); (v) casos ambíguos e 'entres' - indícios de estágios $A / B$.

Em síntese, daí parece emergir como conector em uma trajetória com as seguintes etapas principais: dêixis espacial (apontamento para o mundo) > anáfora espacial (apontamento para um lugar mencionado anteriormente, criando-se uma relação de co-referência) $>$ anáfora discursivalintrodução de efeito (apontamento para uma informação antes referida, apresentada como causa da informaçãoconseqüência que se segue a dari) $>$ introducão de efeito $>$ seqüienciação temporal, seqüenciação textual e adversão (quatro funções vinculadas ao plano da conexão de partes do discurso que possuem como propriedade em comum o apontamento para a informação prévia e para a informação subseqüente, criando-se um laço coesivo que dispara, no interlocutor, a busca por inter-relações mais específicas). Cada uma dessas etapas de mudança é caracterizada pelo surgimento de uma inovação vinda de usos anteriores de daí, inovação que foi aceita, rotinizada e conservada pelos usuários da língua.

\section{Referências Bibliográficas}

BRAGA, M. L. E aí se passaram 19 anos. In: PAIVA, M. da C.; DUARTE, M. E. L. (Orgs.) Mudança lingüística em tempo real. Rio de Janeiro: Contra Capa/FAPERJ, 2003. p. 159-174.

CASTILHO, A. T. A gramaticalização. Cadernos de Estudos Lingüísticos e Literários, v. 19, p. 25-64, 1997.

COSTA, S. B. B. Advérbios e locuções adverbiais no limiar do português moderno. In: SOARES, M. A.; ARAGÃO, M. S. S. de (Org.). 
JORNADA DE ESTUDOS LINGÜÍSTICOS, 16., Anais... v. 1. Fortaleza: UFC/GELNE, 2000. p. 227-232.

CRAIG, C. Ways to go in Rama: a case study in polygrammaticalization. In: TraugotT, E. C.; HeIne, B. (Eds.) Approaches to grammaticalization. v. 2. Amsterdam: John Benjamins, 1991. p. 455492.

CRISTOFARO, S. Grammaticalization and clause linkage strategies: a typological approach with particular reference to Ancient Greek. In: RAMAT, A. G.; HOPPER, P. J. (Eds.) The limits of grammaticalization. Philadelphia: John Benjamins, 1998. p. 59-88.

CUNHA, A. G. da. Dicionário etimológico Nova Fronteira da língua portuguesa. 2. ed. Rio de Janeiro: Nova Fronteira, 1991.

FILLMORE, C. J. Toward a descriptive framework for spatial deixis. In: JARVELLA, R. J.; KLEIN, W. (Ed.) Speech, place and action: studies in deixis and related topics. New York: John Wiley and Sons, 1982. p. 31-59.

FRAJZYNGIER, Z. The de dicto domain in the language. In: TRAUGOTT, E. C.; HEINE, B. (Eds.) Approaches to grammaticalization. v. 1. Amsterdam: John Benjamins, 1991. p. 219252.

GIVÓN, T. On understanding grammar. New York: Academic Press, 1979.

HARRIS, A.; CAMPBELL, L Reanalysis. In: Historical syntax in cross-linguistic perspective. Cambridge: Cambridge University Press, 1995. p. 61-96.

HEINE, B. Grammaticalization. In: JANDA, R.; JOSEPH, B. (Eds.) The handbook of historical linguistcs. Oxford: Blackwell, 2003. p.624-647. 
et. al. Grammaticalization: a conceptual framework. Chicago: University of Chicago Press, 1991.

HOPPER, Paul J. On some principles of grammaticization. In: TRAUGOTT, E.; HEINE, B. (Eds.) Approaches to grammaticalization. v. 1. Amsterdam: John Benjamins, 1991. p. 1735.

The paradigm at the end of the universe. In: RAMAT, A. G.; HOPPER, P. J. (Ed.) The limits of grammaticalization. Amsterdam: John Benjamins, 1998. p. 147-158.

.; TRAUGOTT, E. Grammaticalization. Cambridge: Cambridge University Press, 1993.

HUTCHINS, E. Cognition in the wild. Cambridge: The MIT Press, 1995.

LAURY, R. Demonstratives in interaction: the emergence of a definite article in Finnish. Amsterdam: John Benjamins, 1997.

LiMA BARRETO, A. H. Triste fim de Policarpo Quaresma. São Paulo: Ática, 1990. [1ª ed.: 1915]

MARCUSCHI, L. A. A hesitação. In: NEVES, M. H. de O. (Org.) Gramática do português falado. v. VII. Campinas: UNICAMP, 1999. p. 159-194.

NASCENTES, A. Dicionário etimológico resumido. Instituto Nacional do Livro/MEC. s/d.

PEREIRA, E. C. Grammatica historica. São Paulo: Monteiro Lobato, 1923.

RAMAT, A. G. Testing the boundaries of grammaticalization. In: .; HOPPER, P. J. (Eds.) The limits of grammaticalization. Philadelphia: John Benjamins, 1998. p. 107-127. 
ROBERTS, I. A formal account of grammaticalisation in the history of the Romance features. Folia Linguistica Histórica, v. 13, p. 219258, 1993.

; ROUSSOU, A. A formal approach to "grammaticalization". Linguistics, v. 37, n. 6, p. 1011-1041, 1999.

SILVA, R. V. M. O português arcaico: fonologia. São Paulo: Contexto, 1991.

SILVEIRA BUENO, F. da. Grande dicionário etimológicoprosódigo da língua portuguesa. São Paulo: Saraiva, 1965.

STEINBECK, J. As vinhas da ira. Porto Alegre: Globo, 1940.

TOMASELLO, M. (Ed.) The new psychology of language. New Jersey: Lawrence Erlbaum, 1998. 